\title{
A FORMAÇÃO HUMANA NA ESCOLA: CONTRIBUIÇÕES PARA AS POLÍTICAS EDUCACIONAIS
}

\author{
Alonso Bezerra de Carvalho \\ Fabiola Colombani
}

RESUMO: O presente artigo tem a finalidade de realizar reflexões que possam contribuir para uma nova perspectiva no campo da formação humana na escola. De caráter teórico, parte da análise que Adorno e Horkheimer fizeram acerca da promessa não cumprida do esclarecimento e que levou a humanidade a viver um dos momentos mais bárbaros de sua história: o nazismo. Esse processo levou os homens a uma insensibilidade e intolerância em relação ao outro. Na tentativa apontar saídas para uma nova formação do homem, recorremos à noção de amizade como foi abordada por Aristóteles. Embora seja um espaço institucionalizado, a sala de aula pode ser um lugar para transgredirmos e edificarmos maneiras renovadas de nos relacionar. Para além dos conteúdos que nela circulam, a ideia é pensar saídas para se experimentar novas atitudes, novos valores, novos diálogos e novas relações na escola.

PALAVRAS-CHAVE: Ética. Sala de aula. Amizade. Formação humana

\section{INTRODUÇÃO}

Em Ética a Nicômaco Aristóteles dá uma especial atenção ao tema da amizade, considerando-a uma das paixões humanas que deveríamos sempre ter em conta no processo de formação para nos tornar virtuosos, ou seja, a amizade também uma virtude, uma experiência necessária à vida. Mesmo que tenhamos todos os bens, toda riqueza e todo o poder ou que vivamos na pobreza, ou em qualquer outro tipo de infortúnio, não poderíamos passar sem a amizade - sem esse refúgio. Os jovens teriam nela uma forma de evitar os erros da inexperiência, os velhos uma forma de socorro às enfermidades da idade e àqueles que estão na força da idade, ela inspira as belas condutas. A amizade, como um exercício, é uma caminhada que dois seres fazem juntos, em que a ternura, a afeição e a simpatia se manifestam. Nobre e bela, a amizade deve, então, ser louvada como o caminho mais vantajoso que nos leva à excelência moral, à areté.

A areté significa um conjunto de valores (físicos, psíquicos, morais, éticos, políticos) que forma um ideal de excelência e de valor humano para os membros da sociedade, orientando o modo como devem ser educados e as instituições sociais nas quais esses valores se realizam. A areté se refere à formação do áristos: o melhor, o mais nobre, o homem excelente [moral e intelectualmente]. (CHAUÍ, 2002, p. 495).

Uma das condições para essa experiência aretaica está na nossa capacidade de estimarmos e bem querermos ao outro, ou seja, em um processo de benevolência partilhada e recíproca. Essa conclusão aristotélica faz bastante sentido para se pensar o mundo contemporâneo, em especial o papel que a educação escolar pode cumprir no enfrentamento das ações e atitudes intolerantes, desrespeitosas, preconceituosas e violentas que temos observado na sociedade, sendo o nazismo um exemplo histórico e macabro que a humanidade teve que viver e lidar, com consequências danosas até os nossos dias.

Filósofos como Adorno e Horkheimer, fundadores da Escola de Frankfurt, traduziram a desilusão de grande parte dos intelectuais em relação às promessas de transformações do mundo contemporâneo, tendo em vista os acontecimentos que levaram à ascensão do nazismo na Alemanha e que, posteriormente, se alastrou pela Europa.

Os autores que se vincularam a esse movimento intelectual, nascido em 1923, com a criação do Instituto para a Pesquisa Social, em Frankfurt, como Adorno, Horkheimer, Benjamin e Marcuse, entre outros, não se satisfizeram com as diversas análises que pro- 
curavam compreender a vitória do nazismo e a derrota das esperanças revolucionárias. (MATOS, 1993, p. 6).

Lançando mão da filosofia, a Teoria Crítica, outro nome dado a esse movimento intelectual, considerou que é de ordem metafísica a explicação para o fenômeno do totalitarismo que se implantou, sendo o nazismo um deles. $\mathrm{O}$ irracional daí advindo e manifesto pelas atrocidades cometidas, estaria na própria constituição do conceito de Razão, isto é, no próprio modo de exercer a racionalidade, pois em nome de uma racionalização crescente os processos sociais são dominados e manipulados pela ótica da racionalidade científica, marca característica da filosofia positivista. O caráter dinâmico, complexo e mutável da realidade social é submetido a um conjunto de métodos que se coloca como universalizados, homogêneo e unívoco. Inspirada em autores como Max Weber (1864-1920), sobretudo em obras como Economia e Sociedade e $A$ ética protestante e o espírito do capitalismo, a Teoria Crítica constata que há uma perda das relações tradicionais com início da racionalização e da formalização dos laços pessoais, o que promove um processo de desencantamento do mundo. O mundo é despojado de seus aspectos místicos, míticos, sagrados e proféticos, tornando-se mecânico, repetitivo e causal, deixando na alma um grande vazio. Miserável, o homem é conduzido pelos valores de troca, do mercado e o dinheiro torna-se um dos seus grandes fetiches. A relação entre os indivíduos é destruída; o homem é transformado e reduzido a estatuto de coisa.

René Descartes é tomado como o filósofo que instaura essa concepção de mundo na modernidade que sobreleva o papel da razão, de maneira a conhecer e representar as coisas, os objetivos e o fatos por meio de conceitos. O cogito - o pensamento ou a capacidade de pensar - é a instância que assegura esse processo, pois ao não ter mãos, nem pés, nem sangue, pode estabelecer e garantir as verdades, segundo as regras da boa ordenação dos elementos, decompondo em partes as dificuldades e as unificando, em uma palavra, aplicando a razão para o bem conhecer. Nesse movimento intelectual a alteridade, a diversidade, a pluralidade e tudo o que é outro em relação à razão é reconduzido à sua dimensão. Nenhuma possibilidade é dada às paixões, aos sentimentos e à sensibilidade.

Este artigo, portanto, buscará seguir dois caminhos: em um primeiro momento, faremos uma exposição acerca das ideias trazidas pelos frankfurtianos, e em um segundo momento, a contribuição aristotélica para a formação ética do ser humano, principalmente considerando os desafios enfrentados pela educação.

Ao fazer esse percurso, pretende-se contribuir no enfrentamento de um processo histórico que nos últimos tempos se assemelha àquele vivido pela filósofa Hannah Arendt: a banalização do mal. Tentando compreender a Alemanha nazista de sua época, Arendt (1999) chegou a conclusões que indicaram que mesmo o alto nível instrucional de boa parte da sociedade e as especulações filosóficas mais sofisticadas sobre ética e moral de alguns eminentes pensadores alemães não foram suficientemente fortes para conter a barbárie que se instaurou. A finalidade deste artigo não é oferecer um projeto pedagógico ou uma política educacional contra a banalidade do mal, mas tão somente refletir sobre alguns fundamentos e perspectivas para um trabalho educativo que se comprometa com o respeito e a abertura a valores éticos fundamentais, como a justiça, a igualdade, a liberdade, a solidariedade, o diálogo e a tolerância, e que possibilite uma formação e uma prática humana amistosa e plena, como nos ensina a paideia aristotélica. 


\section{A Escola de Frankfurt e as promessas esclarecimento}

No livro intitulado Dialética do Esclarecimento, publicado pela primeira vez em 1947, imediatamente após os extermínios nazistas e à Segunda Guerra Mundial, Adorno e Horkheimer expõem, em um conjunto de textos e fragmentos, o diagnóstico que ambos fazem sobre um dos períodos mais bárbaros que a civilização humana experimentou. Para os propósitos desse artigo nos dedicaremos à análise de dois aforismos - Interesse pelo corpo e Sobre a gênese da burrice -, em que o domínio da natureza é o tema central, como ocorre também em vários outros momentos do livro.

No aforismo Interesse pelo Corpo, os frankfurtianos consideram que há uma contra-história, paralela à oficial que, subterrânea, emerge em momentos fronteiriços da humanidade. Essa história clandestina realiza-se no corpo, vítima de uma civilização que o dilacera, desfigura e recalca seus instintos e paixões, tomando-o objeto de controle e manipulação. Assim afirmam: "sob a história conhecida da Europa corre, subterrânea uma outra história. Ela consiste no destino dos instintos e paixões humanas recalcados e desfigurados pela civilização" (ADORNO \& HORKHEIMER, 1985, p. 190).

A figura de Ulisses na Odisseia de Homero pode ser considerada como a proto-história desse processo de formação do sujeito que domina ou dessa história de dominação. Dominar a natureza significa, portanto, antes de tudo, dominar-se, ter nas mãos a própria natureza. O sujeito esclarecido é aquele que conseguiria sacrificar-se, ainda que isso lhe custe sua expressão mais viva. No momento em que Ulisses se defronta com a possibilidade de ouvir o canto das sereias, ele constrói uma estratégia para afrontar o destino fatal traçado pela natureza, que deve ficar sob os seus domínios. Para evitarem a voz das feiticeiras-sereias e seu "florido prado" e serem tragados para as profundezas do oceano, Ulisses propõe aos companheiros que só ele deve ouvir o "melífluo canto", que promete para quem o ouve mais alegria e instrução, pois tais criaturas são portadoras do conhecimento sobre tudo "quanto acontece sobre a fecunda terra.". Obstruindo com cera os ouvidos de cada um dos companheiros-marujos, as mãos e os pés de Ulisses são amarrados com cordas ao mastro do navio de forma que cada vez que "sentia o coração consumir-se em desejo" e pedisse que fosse solto, embalado pelo canto, deveriam as cordas ser apertadas mais fortemente. (HOMERO, 1985, p. 201-204).

Nessa alegoria homérica é possível perceber, segundo os frankfurtianos, que a história do sujeito é marcada pela renúncia e pelo sacrifício dos sentidos, pela repressão dos instintos e dos desejos. Emerge dessa representação literária a ideia de que as paixões devem ser dominadas e impedidas de se manifestarem, abrindo caminho e espaço para o predomínio da razão como mecanismo de controle e de organização da vida. Viver se reduz à construção de estratégias e de ardis para submeter a natureza a um processo de aniquilamento de sua vitalidade, riscos e imprevistos.

A relação de estranhamento e de repulsão daquilo que pertence ao corpo - as paixões, os instintos e os desejos - representa um momento fundamental da cisão entre sujeito e objeto, que tem marcado a história do pensamento filosófico. Essa relação se afigura como um processo de separação entre uma dimensão não corporal - o espírito, o intelecto, a inteligência, o cogito - que exerce seu senhorio, e o corpo - próprio e o de outros -, visto como objeto a ser conhecido e dominado. De alguma forma, a isso correspondente o processo que cinde o trabalho em corporal e intelectual, entre o mundo sensível e o mundo inteligível, como na alegoria da caverna de Platão 
(1996, pp. 317-318). O corpo e seus componentes tornam-se coisas a serem controladas, possuídas e manipuladas, transformando-se em objeto, em coisa morta. A civilização reifica o corpo.

Platão considera o intelecto ou a inteligência como a instância que confere limites, ordem e medida às coisas, sendo que o pensamento é o conjunto das atividades superiores da alma contrapostas à conjectura e à crença, reunidas sob o nome de opinião (doxa). O mundo no interior da caverna representa o mundo da opinião, das aparências, das coisas destituídas de veracidade, visto que são baseadas naquilo que os sentidos captam: os olhos do corpo. Nessa perspectiva, os sentidos nada mais são do que fontes de conhecimento falso, de conjecturas, crenças, suposições, imagens, pré-conceitos e convenções arbitrárias e mutáveis. O mundo sensível nos dá imagens das coisas tais como nos aparecem e nos parecem, variável de pessoa para pessoa e variável em uma mesma pessoa, dependendo das circunstâncias.

Por outro lado, o mundo fora da caverna representa o ápice da vida intelectual e inteligente. Sair da caverna em direção ao Sol - o mundo inteligível - significa contemplar a realidade em sua essência, sem a influência e vestígios de sensibilidade. É o olho do espírito que entra em atividade na busca das essências verdadeiras. Portanto, o inteligível é o conhecimento verdadeiro que alcançamos exclusivamente pelo pensamento. São as ideias imateriais e incorpóreas de todos os seres ou as essências reais e verdadeiras das coisas.

Essa condenação do corpo como reduto absoluto do mal em oposição ao espírito, tomado como suprassumo do bem, foi - lembram Horkheimer e Adorno - condição primordial para as grandes criações culturais da Europa. Nesse sentido, o corpo foi não só "[...] escarnecido e repelido como algo inferior e escravizado, mas também amado, desejado. Todavia, quando exaltado, o foi sempre como coisa, objeto sem vida, como algo 'proibido', 'reificado', 'alienado'." (ADORNO \& HORKHEIMER, 1985, p. 191).

Nesse contexto, o texto em análise se reveste de pleno significado, pois traz ideias e reflexões ricas para pensarmos e olharmos com mais cuidado aquilo que ocorre em uma sala de aula, sobretudo quando se coloca em discussão o processo de aprendizagem dos alunos, geralmente pautado por uma noção de inteligência que se tornou predominante no mundo ocidental e onde, também as relações interpessoais muitas vezes tornam-se insensíveis e conflituosas.

Portanto, o caminho predominantemente percorrido pela filosofia e o pensamento humano foi construído a partir da concepção de que somos seres racionais, inteligentes, capazes de raciocínios e elaboração de conceitos e ideias e, por isso, basta acessar ou fazer movimentar em nós essa capacidade que nos tornamos superiores a qualquer outro ser vivente. Essa perspectiva pode ser compreendida a partir de algumas expressões-sínteses: de Descartes, o célebre "Penso, logo existo"; de Kant, o "Sapere aude! Tem coragem de fazer uso de teu próprio entendimento." (KANT, 1974, p. 100). Nelas é evidente a defesa do poder da razão de organizar, ordenar o mundo e dar sentido e significado a ele. Pensar, raciocinar e entender são ações reservadas e exclusivas do homem, de forma a pôr o mundo, as coisas e a si mesmo sob o seu domínio. A consequência desse processo no campo da educação parece bastante notória. Tanto a organização do espaço físico quanto as relações interpessoais na escola e na sala de aula se fundam em um ambiente e em uma dinâmica em que há o predomínio do que podemos chamar de dimensão racional. É como se a razão pudesse e definisse tudo.

Lógos, ratio ou razão significam pensar e falar ordenadamente, com medida e proporção, com clareza e de modo compreensível para outros. Assim, na origem, razão é a capaci- 
dade intelectual para pensar e exprimir-se correta e claramente, para pensar e dizer as coisas tais como são. A razão é uma maneira de organizar a realidade (medir, reunir, juntar, separar, contar, calcular) pela qual esta se torna compreensível. (CHAUÍ, 2003, p. 62).

Especialmente na época moderna, essa concepção de razão se implantou e adquiriu o status de guardiã e vanguarda das transformações que vimos acontecer no mundo. As práticas científicas, fundadas na razão, transformaram-se em técnicas que penetraram com seus tentáculos nas mais diversas esferas das atividades humanas. Esse poderio todo se manifestou inclusive em fatos históricos bem recentes: cruel e bárbaro, o nazismo, para se instalar, teve a colaboração de pessoas que pensaram racionalmente sobre a melhor maneira de dominar e exterminar outras pessoas. Semelhantes eliminando semelhantes. Filósofos, sociólogos, médicos, biólogos, engenheiros, psicólogos, pedagogos, etc., tornaram-se algozes de uma política de aniquilação de homens, mulheres e crianças. Tudo foi pensado, planejado e executado racionalmente. Engenheiros e químicos, oriundos dos bancos universitários, calcularam sob medida a funcionalidade de um campo de concentração e da câmara de gás.

Os dois filósofos judeus-alemães, Theodor Adorno e Max Horkheimer, também perseguidos pela política do anti-semitismo, apresentam uma análise crítica desse processo de constituição da ideologia racionalista. Procurando entender por que um discurso que prometia a emancipação humana levou uma nação a uma atitude tão violenta e totalitária, os autores concluem que o esclarecimento prometido não passou de uma profunda calamidade humana. Concluíram que o "esclarecimento" se constituiu, nada mais nada menos, em uma série de fenômenos, dentro dos quais encontramos o processo de racionalização, que rompe com a tradição e faz com que os hábitos de vida, sobretudo modernos, sejam guiados pela lógica do cálculo e da previsibilidade. Nesse processo, o mundo é "desmitologizado", levando o homem moderno a deixar de lado suas crenças antigas, suas paixões, sentimentos, etc., direcionando-o a apostar tão somente nas crenças baseadas na razão. Assim, o que se vê é a "matematização" do conhecimento e da vida, que considera como válido apenas aquilo que é comprovado e testado segundo a lógica racional da ciência moderna.

A consequência direta deste desenrolar histórico é a transformação do saber em aparato de dominação, visto que os detentores do domínio racional executam a prática de dominação política e econômica sobre o mundo, de modo que poder e conhecimento aparecem como sinônimos, levando o sujeito moderno à condição de refém da técnica racional como verdade. $O$ estilo de vida que se apresenta agora é aquele em que os homens deixam-se levar pela aparência da sociedade capitalista e do seu meio de produção. Por fim, tudo agora se torna capaz de passar pelo crivo da técnica, fazendo com que os métodos burocráticos e tecnicistas, baseados na racionalidade, no cálculo e na disciplina, sejam tidos como os mais corretos no desenvolvimento das diretrizes modernas. E com isso, o mundo dos sentimentos e das paixões, o que inclui a experiência da amizade, tende a desaparecer por meio de mecanismos que os reprime.

No outro texto, que agora passamos a analisar, encontramos algumas ideias que podem ser tomadas como significativas para exprimir um novo horizonte para o conhecimento, para a educação e para a formação ética. Na abertura do aforismo Sobre a gênese da burrice, composto de três parágrafos, encontramos essa frase categórica: "o símbolo da inteligência é o caracol 'com a visão tateante', graças à qual [...] ele é também capaz de cheirar." (ADORNO \& HORKHEI- 
MER, 1985, p. 210). Ou esta contida no terceiro parágrafo, que poderia dar o título ao texto: "a burrice é uma cicatriz." (p. 210).

Ambas as frases sintetizam e exprimem de maneira contundente uma crítica que os frankfurtianos fazem ao mundo reificado, dominado e submetido aos ditames racionais. A metáfora do caracol e de sua antena está aqui representando o curso e o percurso de uma vida em que os instintos e os impulsos foram reprimidos e recalcados pela civilização, em que os sentimentos, as paixões e as emoções tiveram que ser recolhidos e retirados "para o abrigo protetor do corpo", ou seja, para uma inatividade e para uma inoperância que o torna algo praticamente morto, nulo e ressequido. Diante dos dramas, dos obstáculos e dos perigos que a existência apresenta, a antena, ou seja, a nossa capacidade de sentir e de nos tornar sensíveis, perde força e praticamente desaparece.

Olhando para a dinâmica de uma sala de aula, por exemplo, é possível perceber que essa situação parece se concretizar de maneira bastante clara. E isso desde a infância, visto que "em seus começos a vida intelectual é infinitamente delicada." (ADORNO \& HORKHEIMER, 1985 , p. 210). Aquela disposição de agir de maneira livre e criativa de uma criança vai aos poucos sendo inibida, instaurando-se no lugar um processo de disciplinamento e controle. É como se houvesse um enclausuramento do indivíduo em si mesmo, não arriscando e agindo apenas na direção daquilo que é certo e indubitável e "só muito hesitantemente ousará sair de novo como um órgão independente." (p. 210. Grifo meu).

$\mathrm{Na}$ sequência do texto, os frankfurtianos continuam a mostrar que esse processo se agrava na medida em que os músculos da antena vão se afrouxando e perdendo sua vitalidade. "O sentido do caracol depende do músculo, e os músculos ficam frouxos quando se prejudica seu funcionamento. O corpo é paralisado pelo ferimento físico, o espírito pelo medo. $\mathrm{Na}$ origem, as duas coisas são inseparáveis." (p. 210).

Quando suspeitamos que um aluno não está se adequando a um processo de aprendizagem pré-estabelecido, planejado e organizado, a tendência é considerá-lo destituído de interesse ou de inteligência. Ao não se encaixar nos padrões que certa concepção de escola e de prática pedagógica se fundamenta, o aluno é considerado burro, mesmo que ele use a sua visão tateante que é capaz de cheirar. $O$ que vale é a inteligência fundada em bases racionais. A sua dimensão ética e estética pouco valor possui. Em uma avaliação dos conhecimentos de qualquer disciplina, praticamente é desconsiderada a multiplicidade de sentidos e significados que movimenta a vida dos alunos. O que significa dizer que a escola está construída física, ideológica e pedagogicamente de maneira a privilegiar apenas um aspecto de suas existências: o racional. Nesse sentido, conhecer é resultado dos trabalhos da razão.

Em um de seus belíssimos textos aforismáticos, Nietzsche expõe de maneira bastante contundente o seu entendimento sobre o que significa conhecer. Para ele, conhecer não é somente compreender intelectualmente (intelligere) uma coisa ou um acontecimento. O processo de conhecimento inicia-se com a manifestação de nossos impulsos, muitas vezes diferentes e contrários entre si. É como se houvesse um movimento no interior de cada um de nós, aceitando, execrando ou deplorando e lamentando aquilo que nos chega e nos toca.

Antes que seja possível um conhecer, é preciso que cada um desses impulsos tenha apresentado seu ponto de vista unilateral sobre a coisa ou acontecimento; posteriormente, surge o combate dessas unilateralidades e deles às vezes um meio-termo, um apazigua- 
mento, um dar-razão a todos, uma espécie de justiça e contrato. (NIETZSCHE, 1978, p. 205, A gaia ciência, §333).

Portanto, é preciso levar em conta que a busca e a conquista do conhecimento não se dá meramente com o exercício de nossa capacidade intelectual. Estamos acostumados desde a tenra idade, e nisso a escola cumpre um papel fundamental, a considerar que os conceitos, as ideias, os juízos, etc., ou seja, os conteúdos ensinados, lidos, interpretados e transmitidos, são resultados de uma atividade racional e consciente e que está sob o nosso controle. Segundo Nietzsche, na verdade "só temos consciência das últimas cenas de reconciliação e cômputos finais desse longo processo." Isso quer dizer que intelligere não é algo conciliador, justo, bom e oposto aos impulsos, mas resultado de "uma certa proporção dos impulsos entre si." Em uma imagem: quando assistimos as belas e comoventes cenas de uma peça teatral, estamos vendo apenas uma pequena parte, talvez a menos importante, de um movimento que se iniciou nos bastidores ou até mesmo anteriormente ao espaço físico do teatro ou onde a peça está sendo representada. $M u$ tatis mutandis, na sala de aula também há movimentações, sentimentos, silêncios e inquietações que nem sempre é levado em consideração no momento do educar, mas que faz muita diferença para as vidas de cada um dos personagens presentes ali. Ou seja, o tão alardeado desejo e empenho para que os alunos tornem-se seres conscientes precisa ser repensado e até mesmo ressignificado, visto que, a continuar assim, estaremos formando seres feridos no corpo e no espírito, sem esperança e insensíveis, conforme o diagnóstico frankfurtiano.

Na perspectiva nietzschiana (NIETZSCHE, 1978, p. 205), pensar consciente é apenas uma parte do que significa pensar em geral, o que quer dizer que "a maior parte de nossa atuação espiritual nos transcorre inconsciente." Haveria em nós um combate permanente entre os impulsos, uma "violenta exaustão súbita", que nos inspira, que nos torna criativos e inventivos. Ao invés de uma interioridade silenciosa e serena, diríamos apolínea, somos dotados também, e desde o início, de uma "interioridade combatente", heróica, dionisíaca. A fortaleza de nosso existir não está em um repouso eterno e divino e em um modo brando e tranquilo de pensar, como é o pensar consciente. Portanto, para Nietzsche, o filósofo, mas podemos estender também ao cientista e ao professor, estaria induzido ao erro se desconsiderasse os impulsos, os sentimentos, as paixões, como componentes importantes da natureza do conhecer.

Com isso, talvez seja pertinente pensarmos se os desafios que emergem do cotidiano da sala de aula são frutos de um processo equivocado ou limitado de prática pedagógica. Em outras palavras, restringir ou fechar a possibilidade dos nossos impulsos se manifestarem pode ser a causa dos enfrentamentos que constantemente surgem no ambiente escolar. Como que dialogando com Darwin, Adorno e Horkheimer vão dizer que

os animais mais evoluídos devem o que são a sua maior liberdade; sua existência mostra que, outrora, suas antenas foram dirigidas em novas direções e não foram retiradas. Cada uma de suas espécies é um monumento de inumeráveis outras espécies cuja tentativa de evoluir frustrou-se desde o início; que sucumbiram ao medo tão logo uma de suas antenas se moveu em direção de sua evolução. A repressão das possibilidades pela resistência imediata da natureza ambiente prolongou-se interiormente, com o atrofiamento dos órgãos pelo medo [...] Tendo sido definitivamente afugentado da direção que queria tomar, o animal torna-se tímido e burro. (1985, p. 210). 
Essa imagem nos ajuda a entender porque, muitas vezes, aquele desejo de saber, a curiosidade e o dinamismo que a criança traz ou leva para a escola são desvalorizados, já que a estrutura escolar se organiza ou está organizada de forma a impedi-los de se manifestarem. Nas palavras dos frankfurtianos, aquele "olhar tateante é sempre fácil de dobrar, ele tem por trás de si a boa vontade, a frágil esperança, mas nenhuma energia constante." (p. 210). A sala de aula torna-se, nesse processo, um lugar minuciosamente regulamentado, em que a imagem do professor diante da lousa e as crianças olhando para frente aparecem como uma proposta ou mesmo uma ação que sintetiza e exprime os propósitos moralizadores e normativos que substanciam as práticas pedagógicas. Essa postura tornou-se tão clássica que às vezes nos custa imaginar outra, apesar das variantes que encontramos ou ouvimos falar por aí.

No diagnóstico proposto por Adorno e Horkheimer chega-se à conclusão de que "a burrice é uma cicatriz". Esse processo de cicatrização diz respeito não apenas aos efeitos que foram, são ou estão sendo causados no corpo físico das crianças: a inibição. A burrice daí decorrente atinge as nossas dimensões éticas e epistemológicas, pois

\begin{abstract}
toda burrice parcial de uma pessoa designa um lugar em que o jogo dos músculos foi, em vez de favorecido, inibido no momento do despertar. Com a inibição, teve início a inútil repetição de tentativas desorganizadas e desajeitadas. As perguntas sem fim da criança já são sinais de uma dor secreta, de uma primeira questão para a qual não encontrou resposta e que não sabe formular corretamente. (1985, p. 211).
\end{abstract}

Aquele dinamismo e desejo de brincar, de criar e de se expandir passa a ser regulado por um aparato institucional que procura homogeneizar todas as vontades e aspirações. É como se houvesse um processo de uniformização das diferenças, daquilo que não é igual. Em um mundo assim, a experiência da amizade corre o risco de ser conduzida por atitudes frias, calculistas e meramente interesseiras. Tudo se torna repetitivo, sem graça e sem esperança.

A repetição lembra em parte a vontade lúdica, por exemplo, do cão que salta sem parar em frente da porta que ainda não sabe abrir, para afinal desistir, quando o trinco está alto demais; em parte obedece a uma compulsão desesperada, por exemplo, quando o leão em sua jaula não para de ir e vir, e o neurótico repete a ação de defesa, que já se mostrara inútil. (ADORNO \& HORKHEIMER, 1985, p. 211)

Todos esses comportamentos seriam resultado do processo de divinização e supervalorização da razão que, instituindo um clima intelectualista, diz de forma aristocrática e autoritária que aquilo que não está submetido a ela não pode ser reconhecido como existente e dotado de qualquer sentido estancando, com isso, o diálogo e esmagando as antenas do interlocutor. A inibição e a repetição se impõem brutalmente, surgindo no lugar da criatividade, dos desejos e da "visão tateante que é capaz de cheirar", que foram reprimidos, "uma cicatriz imperceptível, um pequeno enrijecimento, onde a superfície ficou insensível." (p.211). A inteligência que se instaura faz perder a capacidade de olhar com perplexidade e curiosidade para essa coisa rica que é a vida. Como busca certezas e conceitos, não se é capaz de exercitar "a arte da desconfiança", como pensara Nietzsche.

Segundo Nietzsche, o filósofo precisa praticar uma certa "arte da desconfiança", sendo seu principal instrumento o "martelo" [...] Com Nietzsche os filósofos aprendem que as ideias não são extraídas de um céu filosófico que seria alcançado por meio de uma espécie de contemplação [...] Os conceitos têm uma origem sublunar, que são criações, 
e sofrem por isso as vicissitudes empíricas das experimentações. Os conceitos não estão prontos, à espera de que os filósofos mais argutos, mais votados à sua contemplação, mais amigos da sabedoria, venham resgatá-los de seu recesso suprassensível. Os conceitos têm uma origem, em sua maior parte, baixa. (CARDOSO JR., 2007, p. 37).

Quando praticamos uma educação diferente dessa posição, é praticamente certo que estamos violentando e ferindo de morte a possibilidade de expansão da vida; estamos criando seres deformados, duros, deficientes, cegos e impotentes. Como que desenvolvendo um "câncer em seu interior" e estagnando-os em atitudes fanáticas e sem vida

a violência sofrida transforma a boa vontade em má. E não apenas a pergunta proibida, mas também a condenação da imitação, do choro, da brincadeira arriscada, pode provocar estas cicatrizes [...] Assim também as etapas intelectuais no interior do gênero humano e até mesmo os pontos cegos no interior de um indivíduo designam as etapas em que a esperança se imobilizou e que são o testemunho petrificado do fato de que todo ser vivo se encontra sob uma força que o domina. (ADORNO \& HORKHEIMER, 1985, p.211)

\section{Aristóteles e a Amizade: a sala de aula como lugar de encontro}

Enfim, quando se entra em uma sala de aula, a tendência é sempre considerar que os alunos são dotados de inteligência e por isso estão ali. Prepara-se as aulas, os exercícios, as leituras, etc, levando em conta que eles têm capacidade para compreender o que se diz e o que é sugerido como atividade de aprendizagem. Dotados de uma capacidade racional, no sentido proposto por Descartes, supomos que eles vão desempenhar de maneira satisfatória o domínio dos conteúdos, dos conceitos e das ideias, de tal forma que se tornarão senhores da natureza, das coisas e do mundo.

Da mesma forma, os alunos olham os professores e têm como pressuposto que estes são portadores de uma competência e de uma habilidade para ensinar, visto que também são considerados seres racionais e inteligentes. Na sala de aula ocorreria, portanto, um diálogo entre dois personagens que se não estão no mesmo patamar de conhecimento, pelo menos vão percorrer um caminho de trocas de saberes, sendo que um o transmite e o outro o recebe, reconfigurando aquilo que trouxe de suas experiências cotidianas. Tradicionalmente, essas posturas são as que mais revelaram e ainda revelam o que se passa na prática pedagógica ao longo da vida de alunos e professores. No ponto de partida desse processo está a atitude de considerar a inteligência como estando no centro, regulando as ações que são desempenhadas na sala de aula.

Por meio da inteligência exerceríamos a nossa capacidade de encontrar novos meios para um novo fim, adequando meios existentes a uma finalidade nova, o que nos possibilita encarar de maneira diferente situações novas e inventar novas soluções para elas, resultado das escolhas que temos de fazer entre vários meios e fins possíveis. Nesse nível prático, a inteligência é capaz de criar instrumentos, isto é, de dar uma função nova e um sentido novo a coisas já existentes, para que sirvam de meios a novos fins.

Embora possamos perceber comportamentos inteligentes em alguns animais em uma situação desafiadora para obter alimentos, como é o caso do chimpanzé, é notório que há diferenças entre este e uma criança, visto que esta última ultrapassa a situação imediata de fome e de uso direto dos objetos e preveria uma situação futura para a qual encontra uma solução, transformando os objetos em instrumentos propriamente ditos. 
A criança antecipa uma situação e transforma os dados de uma situação presente, fabricando meios para certos fins que ainda estão ausentes. Ela se lembra da situação passada, espera a situação futura, organiza a situação presente a partir dos dados lembrados, esperados e percebidos, imagina uma situação nova e responde a ela, mesmo que ainda esteja ausente. A criança se relaciona com o tempo e transforma seu espaço por essa relação temporal. A criança representa seu mundo e atua praticamente sobre ele. Sua inteligência difere, portanto, da do animal. (CHAUÍ, 2003, p.160. Grifo do autor).

Sinônimo de razão, intelecto, pensamento, consciência, sabedoria, a inteligência é uma atividade que é por si mesma a mais elevada que há em nós; e entre as coisas cognoscíveis, as mais elevadas são aquelas de que se ocupa a inteligência, como diz Aristóteles. E mais:

\begin{abstract}
é a mais contínua, já que a contemplação da verdade pode ser mais contínua do que qualquer outra atividade. E pensamos que a felicidade tem uma mistura de prazer, mas a atividade da sabedoria filosófica [inteligência] é reconhecidamente a mais aprazível das atividades virtuosas; pelo menos, julga-se que o seu cultivo oferece prazeres maravilhosos pela pureza e pela durabilidade, e é de supor que os que sabem passem o seu tempo de maneira mais aprazível do que os que indagam. (ARISTÓTELES, 1987, p. 188).
\end{abstract}

Ainda na perspectiva aristotélica o intelecto ou a razão exerce no homem uma atividade quase divina, é nossa melhor parte e que nos aproxima dos deuses. Alcançar a idade da razão é como ter a oportunidade de experimentar o que há de melhor em nós e de mais prazeroso na vida.

Ora, quem exerce e cultiva a sua razão parece desfrutar ao mesmo tempo a melhor disposição de espírito e ser extremamente caro aos deuses. Porque, se os deuses se interessam pelos assuntos humanos como nós pensamos, tanto seria natural que se deleitassem naquilo que é melhor e mais afinidade tem com eles (isto é, a razão), como que recompensassem os que a amam e honram acima de todas as coisas, zelando por aquilo que lhes é caro e conduzindo-se com justiça e nobreza. (ARISTÓTELES, 1987, p. 192).

Se essas considerações aristotélicas nos ensina muito e faz compreender o seu interesse pelo humano em sua plenitude, melhor ainda quando nos oferece suas contribuições e análises acerca da dimensão moral. Para ele, o fim da ética é a busca da felicidade, isto é, a realização plena e prazerosa das virtualidades inerentes à natureza humana. Isso significa dizer que quando o homem consegue afinar os desejos e as ações com seu pensamento, agindo em plena consonância com a própria natureza e realizando os fins que lhe são próprios, alcança e experimenta esse sentimento de plenitude que constitui a felicidade, e que é mais do que a honra, o poder, o sucesso ou o prazer puro e simples. "Quando o desejo é guiado pela razão e esta é estimulada pelo desejo, essa harmonia é a fonte da felicidade." (FARIA, 1994, p. 75). Nesse sentido, tomar a noção de amizade pode fazer todo sentido e se tornar uma belíssima contribuição para uma possível superação ou enfrentamento dos reveses que a crença na razão provocou na história, com efeitos perceptíveis na educação. Para Aristóteles, a amizade, como coroamento e expressão viva de uma existência virtuosa, é também fonte de felicidade, isto é, corresponde ao desabrochar pleno da natureza humana em suas dimensões individual e social.

Para Aristóteles, desejar o bem do outro, ser benevolente é uma atitude que não deve ser ignorada pelos homens, pois ela conduz a nos relacionar com as pessoas e a estabelecer uma reciprocidade dos sentimentos e a manifestar ativamente essa reciprocidade. Segundo ele, podemos falar em três espécies de amizade, diferenciando-se somente pelo fim 
visado: aquela dirigida ao bem, ao agradável e ao útil. A amizade fundada na utilidade considera apenas o benefício ou o proveito que pode ser tirado, isto é, a afeição pelo outro está nas vantagens que são esperadas, tendo em vista o interesse próprio, o que denota não uma reciprocidade, mas um amor a si próprio. A amizade agradável, por seu lado, está inspirada no prazer que o outro proporciona, tendo em vista apenas o deleite pessoal. Em ambas, a

[...] amizade nasce somente de circunstâncias acidentais e não de qualidades essenciais do indivíduo amado. Não se ama o outro pelo que ele é, mas pelo que ele pode proporcionar, oferecer. A amizade assim construída pode ser reconhecida como frágil (ARISTÓTELES, 1988, p.33-4).

Por seu lado, a amizade que visa ao bem é perfeita e virtuosa, devendo ser a preferida de todos. Mais rara e mais lenta para se formar, essa amizade é duradoura, dado que pertence ao homem virtuoso considerar os amigos como a si-mesmo e o prazer que experimenta reside nas ações que exprime uma natureza que visa sempre ao bem do outro. Essa semelhança de natureza se funda em uma relação de confiança e de um reconhecimento recíproco: os homens bons e virtuosos são agradáveis e úteis uns aos outros (ARISTÓTELES, 1988, p.34-5). Portanto, a amizade virtuosa inclui e vai além de uma amizade útil e agradável, pois a vida em comum é a característica mais relevante desse tipo de amizade. Como disposição duradoura, gostar de seu amigo significa gostar do que é bom por si-mesmo, o que pressupõe, portanto, uma igualdade, uma partilha da existência.

Experimentar a amizade é considerar a possibilidade de uma vida justa e virtuosa, fundada no compartilhar do que é agradável, no desejo de fazer bem ao outro e de se exercitar na direção de atitudes não baseadas nos interesses individuais, fonte de conflitos permanentes, mas nos colocando como membros de uma comunidade, como pertencentes a uma coletividade.

É recorrente no pensamento aristotélico considerar a prudência (phronésis) como uma das condições para o estabelecimento dessa vida justa e virtuosa, seja nas relações de amizade bem como na de cidadão. No caso do sentimento de amizade, ela deve estar associada ao bom-senso, à moderação, à circunspecção e à ponderação, permitindo deliberarmos corretamente acerca do que é bom para nós e agirmos de acordo com isso. Sem essa disposição, teremos dificuldades em escolher e realizar atos que garantam a amizade. Portanto, exercitar a justa medida é fundamental: ela restabelece entre os desiguais a igualdade, preservando o sentimento de amizade e o equilíbrio da comunidade política. Exercitar bem uma vida de amizade e de cidadania funda-se, assim, em uma deliberação que reflete o que é benéfico, sobre o que é certo, de forma correta e no tempo certo, enfim, a boa deliberação garante alcançar o bem que dura.

A amizade perfeita, sentimento reservado aos homens virtuosos, pressupõe o altruísmo como característica básica que deriva das relações do indivíduo consigo mesmo: desejar o bem de si mesmo é condição para o bem do outro. "O amigo é outro si-mesmo". Agir com prudência e justiça não é apenas um fim que está posto no futuro, mas trata-se de uma condição mesma para nos tornamos prudentes e justos. Enquanto os homens perversos, viciosos, imprudentes, indolentes são marcados por inclinações egoístas, e não gostando de si mesmos tornam-se incapazes de amizade. Segundo Aristóteles:

[...] em uma palavra, eles não têm nada de amável, nada que os leve a gostar deles mesmos, se sentem estranhos com suas próprias alegrias e aflições. Sua alma é um teatro de 
conflitos: uma parte sofre quando se vê forçada a se abster de algumas coisas, enquanto a outra experimenta da alegria (ARISTÓTELES, 1988, p.66).

Uma alma assim atormentada, que se move em várias direções, não pode proporcionar sentimento algum que possa ser atribuído aos homens de bem. A abertura ao outro é a condição plena para uma vida feliz: o amigo sendo um outro si-mesmo proporciona-nos uma satisfação completa. O homem feliz necessita, portanto, de amigos, pois seria absurdo possuir todos os bens e gozá-los solitariamente, sobretudo, porque estamos destinados a viver em sociedade. Dessa forma, a felicidade é o resultado desse exercício de contemplação das condutas virtuosas dos nossos amigos: o homem virtuoso se sentirá alegre e feliz quando convive com as belas ações e se aflige com aquelas que são inspiradas no vício. Em uma palavra, amizade e felicidade são experiências que estão ligadas.

Diferentemente dos animais, que são constituídos somente pela faculdade de sentir, o homem dispõe de algo mais: o pensamento. Sentir e pensar formam a essência da vida humana, revelando não apenas a nossa potência do agir, mas as nossas ações mesmo. Sentir e pensar significa ter consciência de uma vida boa, agradável e virtuosa, representa a alegria do existir. Existir com amigos representa conviver, trocar palavras e pensamentos é partilhar sentimentos. "Uma tal vida com o outro é acessível somente aos homens. Os animais sabem apenas pastar ao mesmo tempo e no mesmo lugar" (ARISTÓTELES, 1988, p.76).

Portanto, o fundamento para a experiência da amizade está em compartilhar uma vida em comum. Viver entre amigos é uma ação política. A amizade, como virtude, ou melhor, tendo em vista a vida feliz e virtuosa, é o meio para compartilhar a prosperidade e suportar as adversidades. A presença de amigos é preciosa, seja na alegria, seja na tristeza, tornando as dores leves e toleráveis. "A amizade é uma comunidade, em que os sentimentos que temos por nós-mesmos, temos por um amigo. Como desejamos a nossa própria existência, desejamos a de um amigo e a consciência de sua existência se atualiza concretamente graça a essa vida em comum" (ARISTÓTELES, 1988, p.79-80). Enfim, viver na companhia dos amigos nos faz crescer, corrigir-se mutuamente e tornar modelos uns para os outros, confirmando a máxima: é dos seres virtuosos que aprendemos a virtude.

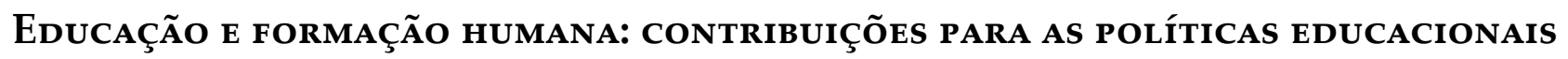

Essas reflexões a partir de Aristóteles nos conduz a uma possibilidade de construção de um espaço, em que as relações humanas tomem a amizade como fonte inspiradora e, com isso, transformem as barreiras das inevitáveis diferenças entre professores e alunos tão insignificantes que os problemas acabem fluindo de forma positiva e significativa. Antes, a proposta aqui é tomar essas ideias aristotélicas, sobretudo a de amizade, como uma possibilidade de compreendermos e enfrentarmos, de maneira que não se repita em lugar nenhum, o que aconteceu em Auschwitz.

A partir do que também diagnosticaram Adorno e Horkheimer põe-se para nós hoje um desafio que precisa começar a ser enfrentado no exato espaço da sala de aula. O professor - representante do espírito e da técnica racional - situando-se como ponto de convergência de todos os acontecimentos, como protagonista maior do ensino - instrutor, moralista e adestrador de condutas -, parece que está condenado ao fracasso. O mesmo cabe ao aluno, que não pode mais ficar apenas recebendo o que o professor diz e, assim, viver o resto de sua vida de cabeça dobrada 
e sem vontade própria, desenvolvendo em seu íntimo um "câncer" que o torna imobilizado em direção à esperança. Para tanto, talvez seja necessário uma ampliação do papel que o pensamento ou o ato de pensar pode adquirir nesse desafio, como propunha Hannah Arendt. Na esteira de sua argumentação, a atividade do pensar poderia consistir em um distanciar-se do mundo, mas não fazendo dele ou trocá-lo por um mundo inteligível em busca de critérios e normas para o mundo sensível. Pensar é a ação de ver o mundo, desde fora, ou seja, desde uma posição privilegiada para ver as ações cotidianas, ressignificando-as.

Quando estou pensando não me encontro onde realmente estou; estou cercada não por objetos sensíveis, mas por imagens invisíveis para os outros. É como se eu tivesse me retirado para uma terra dos invisíveis, da qual nada poderia saber, não fosse esta faculdade que tenho de lembrar e imaginar. O pensamento anula distâncias temporais e espaciais. Posso antecipar o futuro, pensá-lo como se já fosse presente, e lembrar do passado como se ele não tivesse desaparecido. (ARENDT, 1995, p. 67)

Uma política educacional que garanta uma formação que enfrente a banalidade do mal, concretizada em inúmeros casos de injustiças, violências e intolerâncias desses tempos sombrios, deveria garantir aos educadores as condições para que, diante dos desafios na sala de aula, eles possam educar para e no pensamento e, consequentemente, para e em valores. Ou seja, educar na perspectiva do pensamento e ressignificar o mundo que habitamos é uma urgência. Na sala de aula, cabe garantir e reconhecer que a existência é diferenciada, plena de vida e rica de sentimentos, paixões, desejos, por meio da busca de experiências novas e inovadoras. As certezas, os conceitos, o mundo das ideias, devem ser uma parte de um processo que muitas vezes nem nós mesmos conhecemos em seu todo. Somos incompletos e finitos. Conhecer, ser, agir, falar, pensar são partes de nós que se movimentam por forças cuja capacidade nem sempre temos dimensão. Afinal, somos seres passionais ao mesmo tempo em que somos seres pensantes, o que quer dizer, enfim, que a ética deve se fincar de maneira mais funda no ambiente escolar, isto é, na sala de aula, de forma a enfrentarmos com destemor as causas que levam alunos e professores a petrificarem as suas existências

Se na escola prevalece uma noção e uma perspectiva racional-epistemológica, nos termos que abordamos acima, e que tem contribuído para refletirmos, calcularmos e elaborarmos métodos e técnicas úteis à prática pedagógica, talvez agora cumpre ver o que seria da sala de aula e da aula se a pensássemos também do ponto de vista da ética, de maneira a fazermos uma experiência de ouvir e olhar o outro. A criança ao chegar à escola amplia, aprofunda, e até mesmo pode transgredir, o espaço e os valores domésticos. Ela sai do mundo da casa (oikós) em direção ao mundo da pólis e do ethos. Portanto, é na escola e na sala de aula que ocorre "o evento onde se dá o começo da ação política [e ética] pela qual se instaura a confirmação do eu pelo outro e deste por aquele, em suma: o diálogo" (VON ZUBEN, 1996, p.128). Portanto, essas dimensões - a epistemologia e a ética -, podem garantir a formação mais plena do indivíduo.

Vivemos em um tempo que, se há resquícios fortes do nazismo, as políticas educacionais de qualquer tipo, entre elas a formação de professores e as práticas pedagógicas que são implementadas nas escolas, talvez devessem se preocupar cada vez mais em buscar caminhos que impeçam a volta ou a existência de valores e atitudes que geram situações de intolerância, de desrespeito, de discriminação e, por fim, de violência. Uma escola e uma educação, que ao se responsabilizar por uma parte do processo da formação humana, devem ter o compromisso de entregar à sociedade um indivíduo que, no mínimo, 
rechace qualquer tipo de ação e/ou discurso que lembre as atrocidades promovidas nos campos de concentração e câmara de gás nazista. Ao se restringir apenas à dimensão racional-epistemológica ou a uma visão estritamente moralizante e prescritiva das ações humanas, a educação perde um amplo leque de possibilidades para a formação. Retomando a noção a paideia, tal como os gregos a abordaram, pode ajudar nesse novo horizonte a ser construído. Hoje é necessário considerar que a ética e até mesmo a política, entre elas as políticas educacionais, não são mais essenciais ou exclusivamente, as que se referem ao poder e aos valores, respectivamente. Elas tornaram-se tudo aquilo que, sem ter metro prévio, exige uma ação criativa, pressuposto da paideia. Agir política e eticamente é moldar a própria vida sem seguir uma regra anterior, unívoca e homogênea, ou seja, como algo meramente racional, calculado e previsto.

Não existem mais regras pré-definidas sobre como agir na profissão, no amor, nos tratos e contratos que firmamos, e que, sendo cumpridas, assegurariam o sucesso, ou pelo menos a certeza moral de haver cumprido. Precisamos, constantemente, inventar novas formas de ação e de associação. Deparamo-nos, sem número de vezes, com a dificuldade, o imprevisto, o fracasso. Temos à nossa frente o alcance devastador da fortuna sobre nossas vidas, e o espaço sem nenhuma garantia em que tentamos fazer uso da virtú, da ação criadora que procura moldar o futuro (RIBEIRO, 2004, p.84).

Nesse sentido, a escola do pluralismo é uma escola onde habita a dimensão ética e a dimensão política. O que significa dizer que a lei não é mais dada à escola, ela está por se fazer. Esta lei a construir é a fonte e o meio de legitimar o vivre-ensemble na escola. A escola não é somente objeto da política ou de uma política, antes e sobretudo, representa experiência e elaboração do político. Ela é o que explicita os sujeitos em suas histórias e em seus encontros, sobre a base da relação e da solidariedade. Mas isso é possível no mundo das incertezas? É precisamente porque há a incerteza que a educação torna-se pensável e possível na realidade contemporânea. O desafio da escola, da educação, é encontrar, pois sempre se trata de encontro, um caminho, sendo que, hoje, parece-nos que ele está a construir. (BOURGEOIS; COSTA-LASCOUX, 2004).

Não é a mesma coisa ser aluno e ser professor: um está diante do outro, do ponto de vista da sala de aula. Pode ser catastrófico construir estratégias para superar as distâncias, a hierarquia e a representação social. No entanto, pertencem ao mesmo grupo, à mesma convivência, ao mesmo ambiente e o professor pode acabar sendo o amigo mais experiente que serve de mediador entre a sala de aula e o mundo extraclasse. O jogo ético da relação social é evidente e, por isso, exige habilidade para uma possível experiência da amizade. Para tanto,

\footnotetext{
é necessário deixar de ser professor para poder sê-lo. Isto significa obrigatoriamente que toda relação social [...] implica um elemento que une, que é a amizade. Este elemento fundamental é o sentimento de uma cumplicidade, de uma comunidade essencial sobre as coisas mais importantes. Na relação do professor com seus alunos está o fato da partilha de uma certa imagem do que se deve ser alguém, de ter em comum uma forma de sensibilidade e de acolhimento ao outro (VERNANT, 1995, p.194).
}

Neste sentido, ao trazermos para o centro das discussões o diálogo na sala de aula, o fazemos com a finalidade de pensar a escola como um espaço potencializador de amizade, onde o amigo sirva de mediador para que o outro sinta-se acompanhado em suas descobertas e reflexões e, com isso, construírem juntos possíveis saídas para os dramas e dilemas que costumam surgir no âmbito escolar.

Vislumbrar a possibilidade da amizade nas salas de aula pode ser a pré-condição intransferível de uma co-cidadania, de uma cidadania-em-comum, de forma um homem virtuoso. Deste 
modo, podemos acreditar que a escola pode ser um espaço de crescimento, onde a educação desempenhe seu papel de uma forma democrática e humanizadora, sem ser arbitrária. E os educadores construam relações mais sólidas sem serem normatizadores, podendo com os alunos construírem alternativas, primeiro como reflexões e, depois, como elaborações de propostas para enfrentar os problemas e questões que a realidade escolar nos coloca.

Enfim, mais do que garantir um processo de subjetivação, devemos abrir caminhos para a intersubjetivação. A amizade, nos termos aqui discutidos, pode certamente contribuir para essa experiência, de maneira que possamos reelaborar um passado trágico e que não pode ser esquecido.

\title{
HUMAN TRAINING AT SCHOOL: CONTRIBUTIONS TO EDUCATIONAL POLICIES
}

\begin{abstract}
The aim of this article is to carry out reflections that can contribute to a new perspective in the field of human formation at school. Theoretical, part of the analysis that Adorno and Horkheimer made about the unfulfilled promise of enlightenment that led humanity to live one of the most barbaric moments in their history: the nazism. This process led men to insensitivity and intolerance concerning the other. In an attempt to point out ways for a new formation of man, we resort to the notion of friendship as approached by Aristotle. Although it is an institutionalized space, the classroom can be a place for us to transgress and build new ways of relating. In addition to the contents that circulate in it, the idea is to think about ways to experience new attitudes, new values, new dialogues and new relationships at school.
\end{abstract}

KEYWORDS: Ethics. Classroom. Friendship. Human formation

\section{REFERÊNCIAS}

ADORNO, T. \& HORKHEIMER, M. Dialética do Esclarecimento. Rio de Janeiro: Zahar, 1985.

ARENDT, H. A vida do espírito: o pensar, o querer, o julgar. Rio de Janeiro: Relume Dumará, 1995.

. Eichmann em Jerusalém: um relato sobre a banalidade do mal. São Paulo: Companhia das Letras, 1999.

ARISTÓTELES. Éthique à Nicomaque. Paris: Hatier, 1988

Ética a Nicômaco. São Paulo: Nova Cultural, 1987. (Os pensadores, v. 2)

CARDOSO JR., H. R. A amizade como paisagem conceitual e o amigo como personagem conceitual, segundo Deleuze e Guattari. In: Kriterion. vol.48, no.115, Belo Horizonte, 2007, pp. 33-45.

CHAUÍ, M. Convite à Filosofia. São Paulo: Ática, 2003.

Introdução à História da Filosofia: dos pré-socráticos a Aristóteles. São Paulo: Companhia das Letras, 2002.

FARIA, M. C. B. Aristóteles: a plenitude como horizonte do ser. São Paulo: Editora Moderna, 1994. HOMERO. Odisseia. Trad. Carlos Alberto Nunes. Rio de Janeiro: Tecnoprint, 1985 (canto XII, p. 201204).

KANT, I. Textos Seletos. Petrópolis: Editora Vozes, 1974.

MATOS, O. C. F. A Escola de Frankfurt: luzes e sombras do Iluminismo. São Paulo: Editora Moderna, 1993.

Filosofia a polifonia da razão: filosofia e educação. São Paulo: Scipione, 1997.

NIETZSCHE, F. Obras incompletas. São Paulo: Abril Cultural, 1978.

PLATÃO. A República. Lisboa : Fundação Calouste Gulbekian, 1996.

RIBEIRO, R. J.. Ética e ação política na modernidade. In: MIRANDA, D. S. (org.). Ética e cultura. São Paulo: Perspectiva/SESC São Paulo, 2004, pp. 65-88. 